\title{
OS SIGNOS DO CONSUMO, DISCURSOS, CIRCULAÇÃO E APROPRIAÇÕES
}

\author{
Eneus Trindade ${ }^{1}$ \\ Clotilde Perez ${ }^{2}$
}

A Revista Signos do Consumo Volume 6 Número 2 traz nesta edição uma discussão sobre discursos do consumo em suas estratégias de comunicação em marketing, bem como discute aspectos da circulação desses discursos e formas de apropriações dos sujeitos consumidores por meio de processos de interação e usos midiáticos.

Abre este número o texto Análise semiodiscursiva em marketing: um estudo sobre embalagens de leite longa vida, de autoria coletiva de Edileide de Souza Bausen Ribeiro Mestre em Administração pela Universidade FUMEC (2011) e Professora Assistente da Agência Experimental Conceito do curso de comunicação social do Centro Universitário Metodista Izabela Hendrix (2010), Plínio Rafael Reis Monteiro Doutor em Administração pela UFMG, Professor da Universidade FUMEC, integrando o corpo docente dos cursos de Mestrado e Doutorado em Administração e da Coordenação do Curso de Certificação MBA e Luiz Cláudio Vieira de Oliveira - Doutor em Letras (1991), pela Universidade Federal de Minas Gerais. Atualmente é Professor Adjunto III da Universidade FUMEC, nos Cursos de Mestrado e Doutorado em Administração. Tem experiência na área de Letras, com ênfase em Semiótica e Gustavo Quiroga Souki - Doutor em Administração pela Universidade Federal de Lavras (2002). Atualmente é Professor do Curso de Mestrado em Administração e de Cursos de MBA do Centro Universitário UNA. Os autores apresentam resultados de um estudo que mistura semiótica de análise de embalagens e procedimentos de grupos de discussão para análise dos vínculos de sentidos entre marcas de leite e seus consumidores.

\footnotetext{
${ }^{1}$ Professor Livre Docente do Departamento de Relações Públicas, Propaganda e Turismo da ECA/USP. Possui pós-doutorado em Antropologia Visual pela Universidade Aberta de Portugal. Doutor e Mestre em Comunicação pela ECA/USP. Docente do PPGCOM/ECA/USP na área de teoria e pesquisa em comunicação e Vice-coordenador do Grupos de Estudos Semióticos em Comunicação, Cultura e Consumo CNPq/ECA/USP.

${ }^{2}$ Professora Livre Docente em Ciências da Comunicação do Departamento de Relações Públicas, Propaganda e Turismo da ECA/USP. Possui pós-doutorado em Comunicação pela Universidade de Murcia-Espanha. Doutora em Comunicação e Semiótica pela PUC-SP, Mestre em Administração pela PUC-SP. Docente do PPGCOM/ECA/USP na área de interfaces sociais da comunicação. Coordenadora dos Grupos de Estudos Semióticos em Comunicação, Cultura e Consumo CNPq/ECA/USP.
} 
Os signos do consumo, discursos, circulação e apropriações

de Eneus Trindade e Clotilde Perez

$\mathrm{O}$ segundo texto intitula-se Efemeridade e consumo contemporâneo: a circulação do capital no contexto da obsolescência programada de Silvânia Mineira Ribeiro Sotttani, Doutoranda do Programa de Pós-Graduação em Comunicação e Cultura da Universidade Federal do Rio de Janeiro. Mestre em Ciências Sociais pela Universidade Federal de Juiz de Fora. O trabalho realiza uma reflexão teórica e crítica sobre a circulação midiática no contexto do consumo contemporâneo, apontando para a importância dos processos de obsolescência programada na construção dos sentidos de consumo.

$\mathrm{O}$ terceiro artigo Famílias, animais de estimação e consumo: um estudo do marketing dirigido aos proprietários de animais de estimação, resgata uma dimensão do consumo doméstico que merece atenção nos estudos do consumo e que se refere à presença dos animais de estimação na vida cotidiana, bem como do conjunto de marcas que midiatizam a vida dos proprietários de animais. O texto é de autoria de Lavínia Davis Rangel Pessanha - Pesquisadora Titular da Escola Nacional de Ciências Estatísticas e Professora do Mestrado em Estudos Populacionais e Pesquisas Sociais e de Roberto Luís da Silva Carvalho - Mestre em Estudos Populacionais e Pesquisas Sociais. Professor do Instituto de Educação, Agricultura e Ambiente. Ambos da Universidade Federal do Amazonas.

O quarto artigo Publicidade contemporânea: Produtividade discursiva e processos de sedução, de autoria de Rosália Maria Netto Prados Professora pesquisadora do Programa de Mestrado em Políticas Públicas da Universidade de Mogi das Cruzes e Luci Mendes de Melo Bonini - Doutora em Comunicação e Semiótica pela PUC-SP. Coordenadora do Mestrado em Políticas Públicas da Universidade de Mogi das Cruzes, aborda pela análise do discurso com base na Semiótica discursiva o estudo de processos de produção de sentido nos textos de campanhas publicitárias contemporâneas, observando questões da subjetividade. Para esta análise foi selecionada uma campanha, Johnnie Walker, apresentada na mídia em 2013.

$\mathrm{O}$ quinto artigo, Comunicação de mercado em um ambiente pós-moderno: a imaterialidade em cena, de Renata Barreto Malta - Professora efetiva do Departamento de Comunicação Social da Universidade Federal do Sergipe e Daniel dos Santos Galindo - Professor Titular da Universidade Metodista de São Paulo e professor da Escola Superior de Propaganda e Marketing, discutem com uma abordagem teórica e a empírica, o objetivo de "confirmar uma mudança da práxis publicitária na qual elementos materiais e funcionais passam a ser minimizados e elementos imateriais e 
Os signos do consumo, discursos, circulação e apropriações

de Eneus Trindade e Clotilde Perez

intangíveis evidenciados." O campo teórico-conceitual está alicerçado nos Estudos Culturais nas percepções sobre a pós-modernidade em suas relações com o consumo.

O sexto artigo, Abra a felicidade - o discurso da Coca-Cola no caso "Rato na garrafa": consumo, cotidiano e sujeito, recupera a os efeitos de sentidos da circulação midiática da informação de um consumidor que havia encontrado um rato dentro de uma embalagem de Coca-Cola, acionando a empresa judicialmente. A reflexão de autoria de Jéssica de Cássia Rossi - Doutoranda em Ciências Sociais da FFC-UNESPMarília; e Marcelo da Silva - Doutorando em Comunicação Social pela Universidade Metodista de São Paulo, mostra os desafios da comunicação organizacional nos tempos de uma nova circulação midiática que da voz aos consumidores gerando outros embates à comunicação da marca de atuação mundial.

Já o sétimo artigo, Diretrizes para pensar a midiatização dos rituais de consumo nas telenovelas brasileiras, de autoria da Doutoranda Rosana Mauro e do Prof. Eneus Trindade, ambos do PPGCOM-USP, discute o conceito de consumo midiatizado aplicado ao produto cultural telenovela, apresentando as bases para a análise da lógicamídia (promocional e de classe social) que se apresenta nestes produtos midiáticos, sob a manifestação de representações de rituais de consumo, passíveis de serem apropriados pelos receptores-consumidores no contexto brasileiro, constituindo um modo de expressão dos mundos midiatizados.

O último artigo, Usuário-Mídia e Práticas de Consumo no Contexto da Recepção em Comunicação Digital de Midierson Maia - Doutorando e Mestre em Ciências da Comunicação pela ECA/USP, professor da área de comunicação da Universidade São Judas Tadeu e Carolina Terra - Doutora e Mestre em Ciências da Comunicação pela ECA/USP - discute a definição de usuário-mídia e suas implicações no cenário da comunicação digital contemporânea.

E para o desfecho desta edição o conceito de midiatização articula-se como foco central, sinalizando as potencialidades dos estudos do consumo midiático, a partir de duas resenhas: a primeira realizada pelo Doutorando do PPGCOM/ USP Nicolás Llano Linares, referente ao livro Mediatization of Communication de Kurnt Lundby lançado em 2014, que traz uma série de abordagens teóricas e empíricas sobre o conceito de midiatização e o texto A midiatização da cultura e da sociedade: os estudos nórdicos de midiatização e os caminhos para a apropriação brasileira, que traz a resenha feita pela doutoranda do PPGCOM/USP, Lívia Silva de Souza, sobre a obra Midiatização da 
Os signos do consumo, discursos, circulação e apropriações

de Eneus Trindade e Clotilde Perez

Cultura e da Sociedade de autoria do dinamarquês Stig Hjarvard, traduzida em 2014 para o Português pela editora Unisinos.

Por fim, cabe destacar que o ano de 2014 foi um ano difícil com greve e cortes orçamentários que tiveram implicações sobre o trabalho de gestão das edições deste ano. De todo modo, não podemos deixar de agradecer a colaboração dos avaliadores da Revista Signos do Consumo nas duas edições de 2014, a todos nosso reconhecimento e agradecimento pelo valor e sentido de qualidade que agregam a esta publicação: Arlete Petry (Pontifícia Universidade Católica de São Paulo), Aryovaldo de Castro Azevedo Jr. (Universidade de São Paulo), Gino Giacomini (Universidade de São Paulo), Goiamérico Felicio dos Santos (Universidade Federal de Goiás), Mitsuru Yanaze (Universidade de São Paulo) e Sandra Maria Ribeiro de Souza (Universidade de São Paulo).

Desejamos a todos uma boa leitura!

Os Editores 